\title{
Dysregulation of CREB Activation and Histone Acetylation in 3-Nitropropionic Acid-Treated Cortical Neurons: Prevention by BDNF and NGF
}

\author{
Sandra Almeida · Teresa Cunha-Oliveira • \\ Mário Laço • Catarina R. Oliveira • \\ A. Cristina Rego
}

Received: 12 December 2008/Revised: 28 August 2009/Accepted: 8 September 2009/Published online: 25 September 2009

(C) Springer Science+Business Media, LLC 2009

\begin{abstract}
Nitropropionic acid (3-NP), an inhibitor of mitochondrial complex II, leads to metabolic impairment and neurodegeneration. In this study, we investigated the roles of brain-derived neurotrophic factor (BDNF) and nerve growth factor (NGF) in the dysregulation of transcription factors and histone modifying enzymes induced by 3-NP in primary cortical neurons. BDNF prevented the 3-NPinduced decrease in cAMP response-element binding protein (CREB) phosphorylation and CREB-binding protein levels. Both NGF and BDNF counteracted the increase in the levels of histone $\mathrm{H} 3$ and $\mathrm{H} 4$ acetylations and reduced histone deacetylase (HDAC) activity induced by 3-NP. BDNF further led to hyperphosphorylation of HDAC2. Our results support an important role for neurotrophins, particularly BDNF, in preventing detrimental changes in transcription factors and histone acetylation states in cortical neurons that have been subjected to selective mitochondrial inhibition.
\end{abstract}

Keywords CREB-binding protein (CBP) ·

cAMP response-element binding protein (CREB) .

Histone acetylation - Mitochondria .

3-Nitropropionic acid · Cortical neurons

\section{Introduction}

3-Nitropropionic acid (3-NP) is an irreversible inhibitor of succinate dehydrogenase, an enzyme involved in both the tricarboxylic acid cycle and complex II of the electron

S. Almeida $\cdot$ T. Cunha-Oliveira $\cdot$ M. Laço $\cdot$

C. R. Oliveira - A. C. Rego $(\square)$

Center for Neuroscience and Cell Biology, Faculty of Medicine,

Institute of Biochemistry, University of Coimbra,

3004-504 Coimbra, Portugal

e-mail: a.cristina.rego@gmail.com transport chain (Coles et al. 1979; Huang et al. 2006). Chronic administration of 3-NP causes prolonged energy impairment and leads to a pattern of neurodegeneration similar to that seen in Huntington's disease (Beal et al. 1993; Gu et al. 1996; Brouillet et al. 1998). The mechanism of 3-NP-induced neurotoxicity has been shown to involve depletion of ATP, mitochondrial membrane depolarization, accumulation of intracellular $\mathrm{Ca}^{2+}$, excessive mitochondrial reactive oxygen species production, and activation of caspases and calpains (Lee et al. 2002; Bizat et al. 2003; Almeida et al. 2004, 2006). Effects on gene expression have also been demonstrated to play a role in 3-NP-induced toxicity. These alterations appear to occur at the level of specific chromatin modifications, and are an aspect of 3-NP-induced cell death that have not been completely elucidated. Indeed, recent data have shown that apoptosis is accompanied by global changes in histone modifications such as phosphorylation or ubiquitination (Mimnaugh et al. 2001; Talasz et al. 2002) and the activity of many proteins that modify histones is often affected by caspase-mediated cleavage (Casciola-Rosen et al. 1995; Smith et al. 1999).

Brain-derived neurotrophic factor (BDNF) and nerve growth factor (NGF) are members of the neurotrophin family that have been implicated in the regulation of development, and adult synaptic, and neuronal survival ( $\mathrm{Lu}$ et al. 2005). The effects of these neurotrophins are mediated by Trk receptor-induced activation of key signaling pathways including PLC- $\gamma$, Ras/MEK/MAPK, and PI3K/Akt. Signaling culminates in the transcription of neuroprotective proteins through the activation of critical transcription factors such as cAMP response-element binding protein (CREB) and nuclear factor $-\kappa \mathrm{B}(\mathrm{NF} \kappa \mathrm{B}$, Huang and Reichardt 2003). When activated by phosphorylation, CREB binds to its co-activator CREB-binding protein (CBP) and the complex is competent to initiate 
gene transcription (Mayr and Montminy 2001). Similarly, phosphorylation of $\mathrm{I} \kappa \mathrm{B}$ releases the p65:p50 NF $\kappa \mathrm{B}$ heterodimers, which then translocate to the nucleus to initiate transcription. Pro-survival proteins whose expression is dependent on these transcription factors include such proteins as Bcl-2, manganese superoxide dismutase, and BDNF (Saha and Pahan 2006).

In this study, we analyzed the influence of BDNF and NGF on 3-NP-mediated toxicity and its effects on transcription factors, namely CREB, CBP, and NF $\kappa \mathrm{B}$. These transcription factors are involved in the expression of protective proteins, as well as in the acetylation state of histones in cortical neurons. This study may help to determine the role of these transcription factors in neurotrophin-mediated neuroprotection against toxic effects due to mitochondrial dysfunction.

\section{Materials and Methods}

\section{Materials}

Neurobasal medium and B-27 supplement were purchased from GIBCO (Paisley, UK). 3-NP was from Sigma Chemical Co. (St. Louis, MO, USA). $N$-acetyl-Asp-GluVal-Asp- $p$-nitroanilide (Ac-DEVD-pNA) was obtained from Calbiochem (Darmstadt, Germany). BDNF and NGF were from Alomone Labs (Jerusalem, Israel). All other reagents were of analytical grade.

\section{Cell Culture}

Rat primary cortical neurons were prepared as previously described (Almeida et al. 2004). In brief, cerebral cortices were dissected from 16- to 17-day-old fetal rats of the Wistar strain and the cells were dissociated. Cortical neurons were resuspended in Neurobasal medium supplemented with $2 \%$ B-27, $0.2 \mathrm{mM}$ glutamine, $100 \mathrm{U} / \mathrm{ml}$ penicillin, and $0.1 \mathrm{mg} / \mathrm{ml}$ streptomycin and cultured in a humidified incubator at $37^{\circ} \mathrm{C}, 5 \% \mathrm{CO}_{2}$. After 6 days, neurons were pretreated with BDNF $(100 \mathrm{ng} / \mathrm{ml})$ or NGF $(100 \mathrm{ng} / \mathrm{ml})$ for $30 \mathrm{~min}$, and then incubated with $0.3 \mathrm{mM}$ 3 -NP for $24 \mathrm{~h}$. This 3-NP concentration induces apoptotic processes and does not have necrotic characteristics (Almeida et al. 2004). The 3-NP stock solution was prepared in water and brought to $\mathrm{pH} 7.4$ with $\mathrm{NaOH}$.

Subcellular Fractionation

\section{Total Cell Lysate}

Cells were washed twice in ice-cold PBS and resuspended in lysis buffer [20 mM Tris (pH 7.0), $100 \mathrm{mM} \mathrm{NaCl}, 2 \mathrm{mM}$
EDTA, 2 mM EGTA, 1\% Triton X-100] supplemented with $50 \mathrm{mM} \mathrm{NaF}, 1 \mathrm{mM} \mathrm{Na}_{3} \mathrm{VO}_{4}, 1 \mathrm{mM}$ 1,4-dithiothreitol (DTT), $1 \mathrm{mM}$ phenylmethylsulfonyl fluoride (PMSF), and $1 \mu \mathrm{g} / \mathrm{ml}$ protease inhibitor cocktail (chymostatin, pepstatin $\mathrm{A}$, leupeptin, and antipain). The lysates were sonicated on ice for $30 \mathrm{~s}$ and centrifuged $(14,000 \mathrm{rpm}$ for $10 \mathrm{~min}$, Eppendorf Centrifuge 5417R) to remove insoluble material. The supernatants were collected, assayed for protein content using the Bio-Rad reagent according to manufacturer's instructions, and stored at $-80^{\circ} \mathrm{C}$.

\section{Nuclear Extracts}

Nuclear extracts were obtained using a previously described protocol (Santos et al. 2001). In brief, cells were washed twice in ice-cold PBS, resuspended in buffer A $(10 \mathrm{mM}$ HEPES, $10 \mathrm{mM} \mathrm{NaCl}, 3 \mathrm{mM} \mathrm{MgCl} 2,1 \mathrm{mM}$ EGTA, $0.1 \%$ Triton X-100, pH 7.5) supplemented with $50 \mathrm{mM} \mathrm{NaF}$, $1 \mathrm{mM} \mathrm{Na} \mathrm{VO}_{4}, 1 \mathrm{mM}$ DTT, $1 \mathrm{mM}$ PMSF, and $1 \mu \mathrm{g} / \mathrm{ml}$ protease inhibitor cocktail and incubated on ice for $40 \mathrm{~min}$. The nuclei were pelleted by centrifugation at $2400 \times g$ for $10 \mathrm{~min}$ at $4^{\circ} \mathrm{C}$ and resuspended in buffer B $(25 \mathrm{mM}$ HEPES, $300 \mathrm{mM} \mathrm{NaCl}, 5 \mathrm{mM} \mathrm{MgCl} 2,1 \mathrm{mM}$ EGTA, 20\% glycerol, $\mathrm{pH}$ 7.4) supplemented with $50 \mathrm{mM} \mathrm{NaF}, 1 \mathrm{mM} \mathrm{Na}_{3} \mathrm{VO}_{4}$, $1 \mathrm{mM}$ DTT, $1 \mathrm{mM}$ PMSF, and $1 \mu \mathrm{g} / \mathrm{ml}$ protease inhibitor cocktail. After incubation on ice for $60 \mathrm{~min}$, the lysates were centrifuged at $12,000 \times g$ for $20 \mathrm{~min}$ at $4{ }^{\circ} \mathrm{C}$. The supernatants (nuclear extracts) were collected, assayed for protein content using the Bio-Rad reagent, and stored at $-80^{\circ} \mathrm{C}$.

Immunoprecipitation Assay

Total cell lysates $(700 \mu \mathrm{g}$ protein) were precleaned with protein A-Sepharose (Amersham Biosciences, Buckinghamshire, UK) at $4^{\circ} \mathrm{C}$ for $1 \mathrm{~h}$, and the supernatants were then incubated with a rabbit anti-HDAC2 antibody (Abcam, Cambridge, UK, 1:100) on a rotary mixer overnight at $4^{\circ} \mathrm{C}$. $50 \mu \mathrm{l}$ of protein A-Sepharose was added to the immune complexes and tubes were incubated for an additional of $2 \mathrm{~h}$ at $4^{\circ} \mathrm{C}$. Immune complexes were isolated by centrifugation and washed twice with $1 \mathrm{ml}$ of lysis buffer, thrice with lysis buffer plus $500 \mathrm{mM} \mathrm{NaCl}$, and twice with lysis buffer without Triton X-100. The total immunoprecipitated sample was loaded on the gel.

\section{Western Blotting Analysis}

Fifty (total cell lysate) or $35 \mu \mathrm{g}$ (nuclear extract) of protein was separated on SDS-PAGE gels and transferred to polyvinylidene difluoride membranes. After blocking with $5 \%$ non-fat milk in TBS $(25 \mathrm{mM}$ Tris/ $\mathrm{HCl}, \mathrm{pH} 7.6$, $150 \mathrm{mM} \mathrm{NaCl}) / 0.1 \%$ Tween, for $2 \mathrm{~h}$ at room temperature, the membranes were incubated with antibodies directed 
against CBP (Cell Signaling, Danvers, MA, USA, 1:1,000), $\alpha$-tubulin (Sigma, 1:30,000), phospho-CREB (P-CREB) (Cell Signaling, 1:500), CREB (Cell Signaling, 1:750), $\mathrm{NF} \kappa \mathrm{B}$ p65 (Cell Signaling, 1:500), phospho-serine (P-Ser) (Abcam, 1:200), H3 (Upstate, Lake Placid, NY, USA, 1:500), H4 (Upstate, 1:30,000), Acetyl-H3 (Upstate, 1:20,000), or Acetyl-H4 (Upstate, 1:750) overnight, at $4^{\circ} \mathrm{C}$. The membranes were further incubated with the secondary antibody for $2 \mathrm{~h}$ at room temperature and the proteins were visualized using an enhanced chemifluorescence reagent (Amersham Biosciences).

\section{Caspase Protease Activity Assay}

Caspase-like activity was determined as described previously (Almeida et al. 2004). In brief, cortical cells were lysed and centrifuged at 14,000 rpm (Eppendorf Centrifuge 5417R) for $10 \mathrm{~min}$. The resulting supernatants were collected and assayed for protein content using the Bio-Rad reagent, according to manufacture's instructions. Caspase3-like activity was measured using Ac-DEVD-pNA as substrate. Caspase-like activity was calculated as the increase above the control, for equal protein loading $(25 \mu \mathrm{g})$.

\section{Histone Deacetylase Activity}

Histone deacetylase (HDAC) activity was measured with the Colorimetric HDAC Activity Assay Kit (BioVision, CA, USA) according to manufacturer's instructions. In brief, nuclear extracts were incubated with the HDAC substrate Boc-Lys(Ac)-pNA $(10 \mathrm{mM})$ in HDAC assay buffer. After $90 \mathrm{~min}$ at $37^{\circ} \mathrm{C}$, reactions were stopped by adding $10 \mu \mathrm{l}$ of Lysine Developer and further incubated for $30 \mathrm{~min}$ at $37^{\circ} \mathrm{C}$. Absorbance was measured at $405 \mathrm{~nm}$ using a 96-well plate reader (SPECTRA max plus 384, Molecular Devices, Sunnyvale, CA, USA). HDAC activity is presented as the percentage of control (untreated cells). HeLa cell nuclear extracts served as a positive control.

\section{Histone Acetyltransferase Activity}

Histone acetyltransferase (HAT) activity was measured using the colorimetric HAT activity assay kit (Abcam) according to manufacturer's instructions. In brief, nuclear extracts $(10 \mu \mathrm{g})$ were incubated with HAT substrates I and II and NADH generating enzyme in HAT assay buffer, for $4 \mathrm{~h}$ at $37^{\circ} \mathrm{C}$. Absorbance was measured at $440 \mathrm{~nm}$ using a microplate reader (SPECTRA max plus 384, Molecular Devices). HAT activity is presented as the percentage of control (untreated cells). Nuclear extracts provided by the manufacturer were used as a positive control.
Statistical Analysis

Data were expressed as mean \pm SEM of the number of experiments indicated in the figure legends. Comparisons among multiple groups were performed with one-way analysis of variance (ANOVA) followed by the TukeyKramer post-hoc test. Significance was defined as $P<0.05$.

\section{Results}

We have previously shown that treatment of cortical neurons with 3-NP leads to the activation of mitochondrialdependent apoptotic cell death (Almeida et al. 2004). The activation of caspase-3, a well-known mediator of cell death, is reduced by approximately $29 \%(P<0.05)$ and $25 \%(P<0.05)$ when cortical neurons are treated with NGF $(100 \mathrm{ng} / \mathrm{ml})$ or BDNF $(100 \mathrm{ng} / \mathrm{ml})$, respectively, prior to 3-NP $(0.3 \mathrm{mM})$ addition (Table 1). Therefore, we explored the effect of these neurotrophins on the 3-NPinduced dysregulation of transcription factors that promote the expression of protective proteins. As shown in Fig. 1a, 3-NP decreased the levels of the co-activator CBP by approximately 60\% $(P<0.05)$. Similarly, CREB phosphorylation on Ser133 was decreased by approximately $33 \%(P<0.05)$ (Fig. 1b), suggesting a decrease in activated CREB in response to $3-\mathrm{NP}$. BDNF $(100 \mathrm{ng} / \mathrm{ml})$, but not NGF $(100 \mathrm{ng} / \mathrm{ml})$, restored both CBP and CREB phosphorylation levels. Interestingly, BDNF treatment in the absence of 3-NP also increased CBP levels (Fig. 1a). In contrast, the levels of the $\mathrm{NF} \kappa \mathrm{B}$ p65 subunit in nuclear extracts were not affected by 3-NP, NGF, or BDNF treatment (Fig. 1c), indicating that this transcription factor is neither involved in the detrimental effects of 3-NP nor the protective effects of NGF or BDNF.

Given that CBP has acetyltransferase activity (Kalkhoven et al. 2002), we examined the acetylation state of histones $\mathrm{H} 3$ and $\mathrm{H} 4$ (Fig. 2a, b) in response to 3-NP exposure. Despite reduced CBP levels, addition of 3-NP greatly increased the acetylation levels of both H3 (177\%, $P<0.001)$ and $\mathrm{H} 4(260 \%, P<0.001)$. This result suggested that acetylation of histones $\mathrm{H} 3$ and $\mathrm{H} 4$ in response to 3-NP addition is independent of the levels of CBP. We therefore determined the overall activity of HATs and HDACs in our system. We found that HAT activity did not change in response to 3-NP addition, or upon incubation with NGF or BDNF (Fig. 2c). However, 3-NP significantly decreased HDAC activity by about $20 \% \quad(P<0.001$; Fig. 2d) suggesting that the increase in histone acetylation levels observed in response to 3-NP is due to a decrease in HDAC activity with no detectable alteration in HAT 
Table 1 Effects of NGF and BDNF on 3-NP-mediated caspase-3 activation

\begin{tabular}{lll}
\hline Neurotrophin & Control & 3-NP \\
\hline No addition & $1.00 \pm 0.042$ & $2.19 \pm 0.191^{* * *}$ \\
NGF $(100 \mathrm{ng} / \mathrm{ml})$ & $0.89 \pm 0.087$ & $1.56 \pm 0.098^{\#}$ \\
BDNF $(100 \mathrm{ng} / \mathrm{ml})$ & $0.52 \pm 0.057$ & $1.64 \pm 0.078^{\#}$ \\
\hline
\end{tabular}

Cortical neurons were pre-treated with NGF $(100 \mathrm{ng} / \mathrm{ml})$ or BDNF $(100 \mathrm{ng} / \mathrm{ml})$ for $30 \mathrm{~min}$ and further incubated in the absence or presence of $0.3 \mathrm{mM} 3-\mathrm{NP}$ for $24 \mathrm{~h}$. Caspase-3-like activity was measured by following the cleavage of the colorimetric substrate Ac-DEVD-pNA and its activity expressed as the increase in optical density values above the control (untreated neurons). Results were expressed as the mean \pm SEM of five distinct experiments. Statistical analysis: *** $P<0.001$, compared to untreated neurons; ${ }^{\#} P<0.05$, compared to 3-NP-treated neurons in the absence of NGF or BDNF

activity. In addition, both NGF and BDNF counteracted the decrease in HDAC activity caused by $3-\mathrm{NP}$ exposure (Fig. 2d).

Previously, HDAC1 and HDAC2 were shown to become hyperphosphorylated in response to inhibition of protein phosphatases by okadaic acid, and this hyperphosphorylation results in increased deacetylase activity (Galasinski et al. 2002). We therefore tested whether NGF and BDNF treatment affected HDAC2 phosphorylation levels. HDAC2 was immunoprecipitated from control, NGF/ BDNF, 3-NP, or NGF/BDNF plus 3-NP-treated cells, and phosphorylation of HDAC2 was detected with a P-Ser antibody. Our results show that HDAC2 is phosphorylated under basal conditions in untreated neurons, similar to K562 human erythroleukemia cells (Galasinski et al. 2002). Exposure to 3-NP did not affect P-Ser-HDAC2 levels. However, BDNF treatment leads to hyperphosphorylated HDAC2 after a 24-h incubation whether or not 3-NP was present (Fig. 2e). Similar experiments were attempted for HDAC1, but we were not able to detect phospho-HDAC1, most likely because the anti-HDAC1 antibody did not work very well in the immunoprecipitation assay.

\section{Discussion}

Here we show that both NGF and BDNF reduce the acetylation of histones $\mathrm{H} 3$ and $\mathrm{H} 4$ that likely results from reduced HDAC activity caused by 3-NP. In contrast, only $\mathrm{BDNF}$ is able to prevent the reduced CREB phosphorylation and CBP levels induced by 3-NP, and BDNF treatment alone results in hyperphosphorylated (activated) HDAC2.
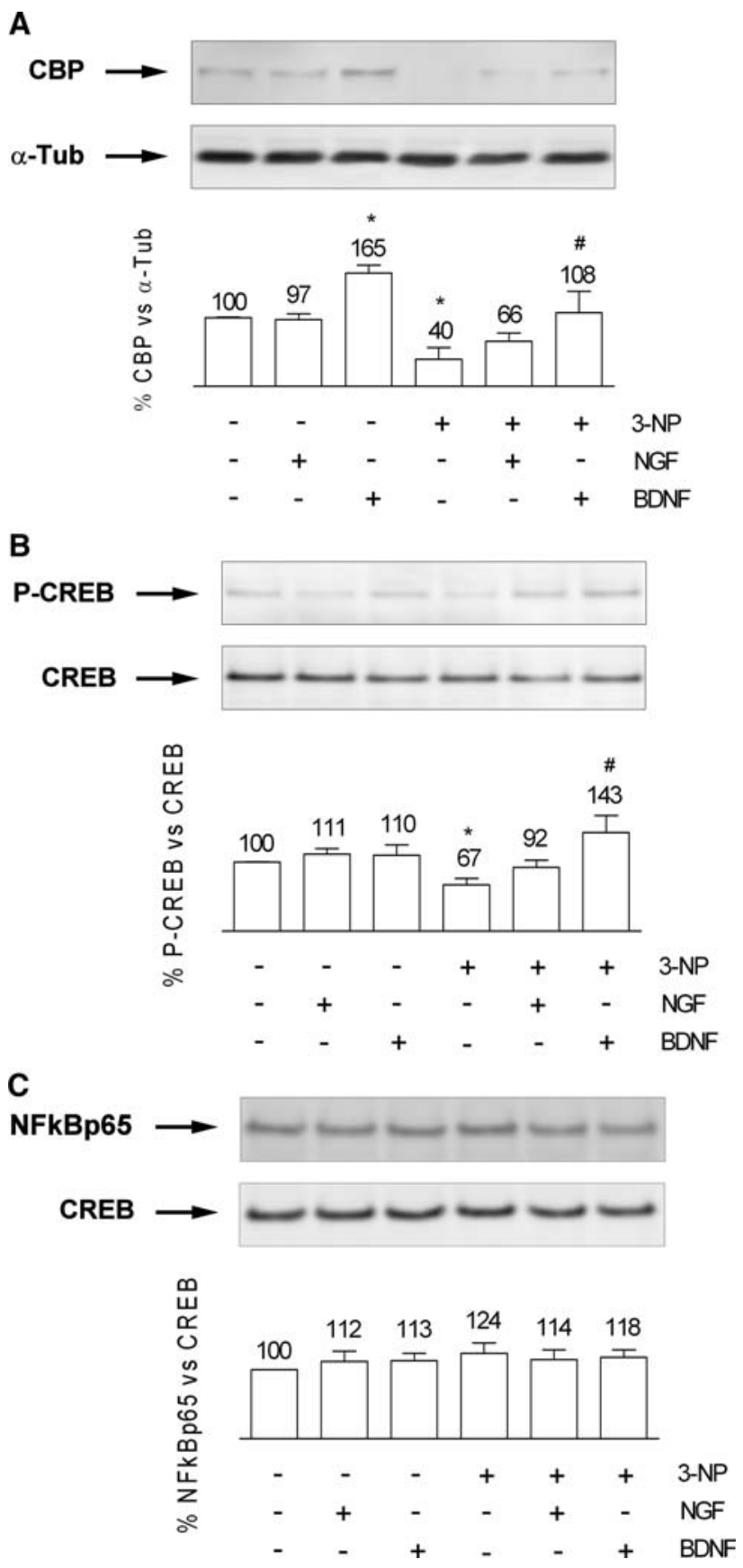

Fig. 1 BDNF prevents the 3-NP-induced decreases in CREB activation and CBP levels. Total cell lysates (a) and nuclear extracts (b, c) were analyzed by Western blotting for CBP (a), phospho-CREB (b), and $\mathrm{NF} \kappa \mathrm{B}$ p65 (c). Blots show a representative experiment from four to six independent experiments producing similar results. Graphs show densitometric analysis performed by normalizing phosphorylated protein signal to the respective total protein band, CREB (a nuclear protein) or $\alpha$-tubulin ( $\alpha$-Tub). Data are the mean \pm SEM of four to six independent experiments. Statistical analysis: ${ }^{*} P<0.05$, compared to untreated neurons; ${ }^{\#} P<0.05$, compared to 3-NPtreated neurons in the absence of NGF or BDNF 


\section{A}

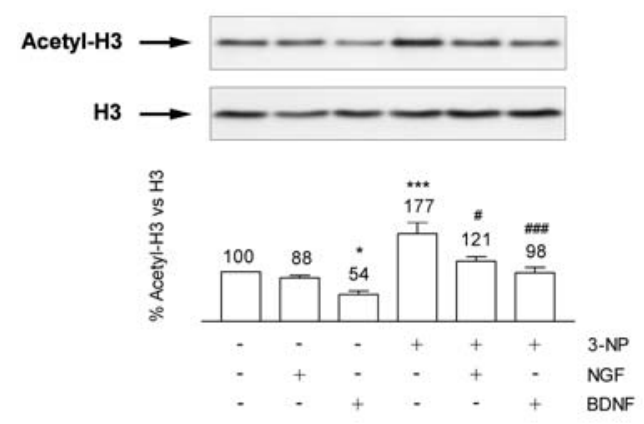

C

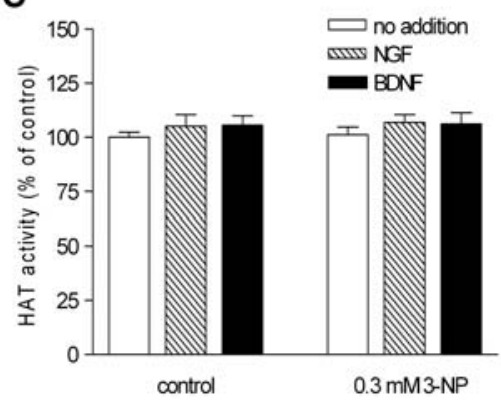

E

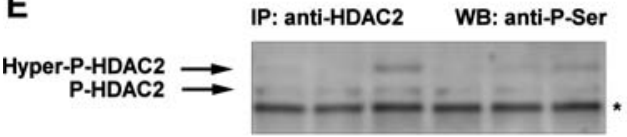

B

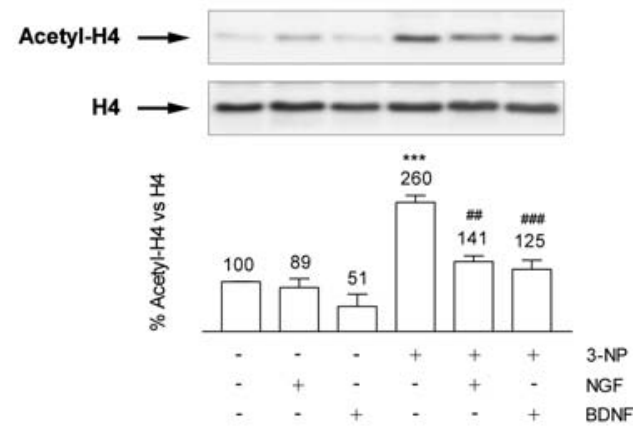

D

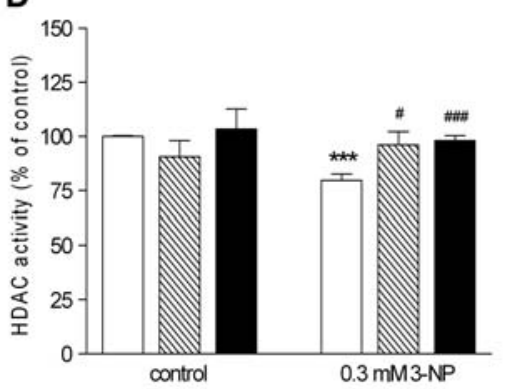

Fig. 2 Effects of NGF and BDNF on histone acetylation in response to 3-NP treatment. Nuclear extracts (a-d) and total cell lysates (e) were analyzed for acetyl-H3 and $\mathrm{H} 3$ (a), acetyl-H4 and H4 (b), HAT activity (c), HDAC activity (d), and P-Ser-HDAC2 (e). a, b Blots show a representative experiment from four to six independent experiments producing similar results. Graphs show densitometric analysis performed by normalizing acetylated protein signal to the respective total protein band. c, $\mathbf{d}$ HAT/HDAC activity is represented as a percentage of control (untreated neurons). Data are the mean \pm SEM of three to seven independent experiments. e HDAC2

CREB is a widely expressed transcription factor whose role in neuronal protection is well established. The phosphorylation status of CREB is critical for its activity, and several protein kinases, such as calcium/calmodulindependent kinase II and IV, protein kinase C, PI3K, Akt, MAPK, and Rsk2, have been reported to promote the activation of CREB (Yamamoto et al. 1988; Matthews et al. 1994; Du and Montminy 1998; Bito et al. 1996; Impey et al. 1998; Perkinton et al. 2002). Phosphorylation on Ser133 was immunoprecipitated and the phosphorylated and hyperphosphorylated forms were detected with an anti-phosphoserine antibody. Shown is a representative blot from three independent experiments producing similar results, and the graph shows the densitometric analysis of the phosphorylated and hyperphosphorylated forms of HDAC2. The lower band seen in the blot (*) is cross-reactive $\mathrm{IgG}$ $(\sim 50 \mathrm{kDa})$ and was used as a loading control. Statistical analysis: $* P<0.05, \quad * * * P<0.001, \quad$ compared to untreated neurons; ${ }^{\#} P<0.05$, \# $P<0.01$, \#\#\# $P<0.001$, compared to 3 -NP treated neurons in the absence of NGF or BDNF

leads to CREB activation and, via interaction with its nuclear partner CBP, promotes the transcription of a large number of genes (Mayr and Montminy 2001). Our results show that 3-NP treatment of cortical neurons decreases both CREB phosphorylation on Ser133 and CBP levels, strongly suggesting reduced CREB-dependent gene expression/ activation. One possible explanation for the decreased CREB phosphorylation would be the activation of phosphatases in response to 3-NP exposure. Several studies have 
shown that protein phosphatase $2 \mathrm{~B}$ and calcineurin, whose expression is regulated by 3-NP (Napolitano et al. 2004), also regulate the duration of CREB phosphorylation (Bito et al. 1996; Liu and Graybiel 1996; Wu et al. 2001). However, the concentration of 3-NP used in this study did not significantly alter calcineurin (Almeida et al. 2004) or protein phosphatase $2 \mathrm{~A}$ (data not shown) activities. The effect of 3-NP on CREB phosphorylation was reversed by BDNF, most likely due to sustained activation of the PI3K/ Akt, the Ras/MAPK, or both kinase pathways, as we have recently demonstrated (Almeida et al. 2009).

The decrease in total CBP levels after 3-NP exposure may be explained by an independent mechanism. CBP has previously been reported to be specifically targeted for cleavage by caspases and calpains at the onset of neuronal apoptosis (Rouaux et al. 2003). Thus, under our experimental conditions, the decrease in CBP could be due to caspase-3, but not calpain activation (Almeida et al. 2004). Indeed, BDNF addition reduces both caspase- 3 activation and the decrease in CBP caused by 3-NP. Nevertheless, although NGF can reduce 3-NP-induced caspase-3 activation, it did not block the decrease in CBP levels caused by 3-NP, suggesting an alternative mode of regulation for CBP levels may also be involved.

In previous studies, Rouaux et al. (2003) reported that a decrease in CBP was correlated with the reduced acetylation of histones $\mathrm{H} 3$ and $\mathrm{H} 4$, and with a reduction in CBP/ p300 HAT activity, even while total HAT activity remained unchanged. Similarly, we found that 3-NP did not alter total HAT activity, but significantly decreased overall HDAC activity, likely explaining why we did not observe a reduction in $\mathrm{H} 3$ or $\mathrm{H} 4$ acetylation. Instead, we observe an increase in both $\mathrm{H} 3$ and $\mathrm{H} 4$ acetylation in cortical neurons upon exposure to 3-NP. Because 3-NP induces caspase-3 activation (Almeida et al. 2004 and Table 1), we hypothesize that caspase-3 plays a role in inactivating HDACs. Conversely, decreased caspase activation induced by both BDNF and NGF treatment could be the mechanism by which the neurotrophins rescue HDAC inhibition and the resultant increase in $\mathrm{H} 3 / \mathrm{H} 4$ acetylation caused by 3-NP. Accordingly, caspase-3 and the mitochondrial pathway have been shown to be critical in triggering HDAC4 processing after a genotoxic stress (Paroni et al. 2004). Other studies have shown that HDAC3 is cleaved in a caspase-dependent manner after the onset of apoptosis (Panteleeva et al. 2004; Escaffit et al. 2007). However, these authors neither observe changes in overall HDAC activity when nuclear extracts were incubated with caspase-3 (Paroni et al. 2004) nor find any increase in H3 and $\mathrm{H} 4$ acetylation following the induction of apoptosis (Escaffit et al. 2007). Therefore, 3-NP may also inhibit HDAC activity through additional mechanisms distinct from apoptosis.
Another possible mechanism for BDNF and NGF modulation of HDACs is that they can be regulated by phosphorylation (Saha and Pahan 2006). HDAC1, HDAC2, and HDAC3 are phosphorylated by a distinct set of kinases, leading to their assembly into repressive complexes that show enhanced enzymatic activity and cause inhibition of gene expression (Saha and Pahan 2006). BDNF and NGF may restore HDAC activity reduced by exposure to $3-\mathrm{NP}$ by positive regulation of the kinases involved in the activation of HDACs. We found that BDNF treatment enhanced HDAC2 phosphorylation, a post-translational modification that has previously been reported to be associated with an increase in deacetylase activity (Galasinski et al. 2002). In contrast, we were unable to detect any increase in HDAC2 phosphorylation after NGF treatment, possibly because NGF is not able to continuously activate the PI3K/Akt and/or Ras/MAPK pathways as BDNF does (Almeida et al. 2009 and unpublished data). NGF protection may thus involve a distinct mechanism. Although the increase in HDAC2 phosphorylation by itself may not be sufficient to change overall HDAC activity, we cannot exclude the possibility that alterations in other HDACs may be occurring. Furthermore, it provides a possible mechanism by which neurotrophins, and in particular BDNF, can regulate HDAC activity and possibly gene expression.

In summary, our data suggest that BDNF and NGF induce positive changes in the levels and activities of transcription factors involved in cell survival. In addition, both neurotrophins counteract chromatin-bound histone acetylation modifications that result upon mitochondrial inhibition. These effects likely explain the neuroprotective role of these neurotrophins in the context of mitochondrial dysfunction.

Acknowledgments We thank Dr. John Miller for proofreading the manuscript. This study was supported by "Fundação para a Ciência e a Tecnologia" (FCT), Portugal, Grant POCI/SAU-NEU/57310/2004.

\section{References}

Almeida S, Domingues A, Rodrigues L, Oliveira CR, Rego AC (2004) FK506 prevents mitochondrial-dependent apoptotic cell death induced by 3-nitropropionic acid in rat primary cortical cultures. Neurobiol Dis 17:435-444

Almeida S, Brett AC, Gois IN, Oliveira CR, Rego AC (2006) Caspase-dependent and -independent cell death induced by 3-nitropropionic acid in rat cortical neurons. J Cell Biochem 98: 93-101

Almeida S, Laço M, Cunha-Oliveira T, Oliveira CR, Rego AC (2009) BDNF regulates BIM expression levels in 3-nitropropionic acidtreated cortical neurons. Neurobiol Dis 35:448-456

Beal MF, Brouillet E, Jenkins BG, Ferrante RJ, Kowall NW, Miller JM, Storey E, Srivastava R, Rosen BR, Hyman BT (1993) Neurochemical and histological characterization of striatal 
excitotoxic lesions produced by the mitochondrial toxin 3-nitroproprionic acid. J Neurosci 13:4181-4192

Bito H, Deisseroth K, Tsien RW (1996) CREB phosphorylation and dephosphorylation: a $\mathrm{Ca} 2+$ and stimulus duration-dependent switch for hippocampal gene expression. Cell 87:1203-1214

Bizat N, Hermel JM, Humbert S, Jacquard C, Creminon C, Escartin C, Saudou F, Krajewski S, Hantraye P, Brouillet E (2003) In vivo calpain/caspase cross-talk during 3-nitropropionic acid-induced striatal degeneration: implication of a calpain-mediated cleavage of active caspase-3. J Biol Chem 278:43245-43253

Brouillet E, Guyot M-C, Mittoux V, Altairac S, Condé F, Palfi S, Hantraye P (1998) Partial inhibition of brain succinate dehydrogenase by 3-nitropropionic acid is sufficient to initiate striatal degeneration in rat. J Neurochem 70:794-805

Casciola-Rosen LA, Anhalt GJ, Rosen A (1995) DNA-dependent protein kinase is one of a subset of autoantigens specifically cleaved early during apoptosis. J Exp Med 182:1625-1634

Coles CJ, Edmondson DE, Singer TP (1979) Inactivation of succinate dehydrogenase by 3-nitropropionate. J Biol Chem 254:5161-5167

$\mathrm{Du} \mathrm{K}$, Montminy M (1998) CREB is a regulatory target for the protein kinase Akt/PKB. J Biol Chem 273:32377-32379

Escaffit F, Vaute O, Chevillard-Briet M, Segui B, Takami Y, Nakayama $\mathrm{T}$, Trouche D (2007) Cleavage and cytoplasmic relocalization of histone deacetylase 3 are important for apoptosis progression. Mol Cell Biol 27:554-567

Galasinski SC, Resing KA, Goodrich JA, Ahn NG (2002) Phosphatase inhibition leads to histone deacetylases 1 and 2 phosphorylation and disruption of corepressor interactions. J Biol Chem 277:19618-19626

Gu M, Gash MT, Mann VM, Javoy-Agid F, Cooper JM, Schapira AH (1996) Mitochondrial defect in Huntington's disease caudate nucleus. Ann Neurol 39:385-389

Huang E, Reichardt L (2003) Trk receptors: roles in neuronal signal transduction. Annu Rev Biochem 24:677-736

Huang LS, Sun G, Cobessi D, Wang AC, Shen JT, Tung EY, Anderson VE, Berry EA (2006) 3-Nitropropionic acid is a suicide inhibitor of mitochondrial respiration that, upon oxidation by complex II, forms a covalent adduct with a catalytic base arginine in the active site of the enzyme. J Biol Chem 281:5965-5972

Impey S, Obrietan K, Wong ST, Poser S, Yano S, Wayman G, Deloulme JC, Chan G, Storm DR (1998) Cross talk between ERK and PKA is required for $\mathrm{Ca} 2+$ stimulation of CREB-dependent transcription and ERK nuclear translocation. Neuron 21:869-883

Kalkhoven E, Teunissen H, Houweling A, Verrijzer CP, Zantema A (2002) The PHD type zinc finger is an integral part of the CBP acetyltransferase domain. Mol Cell Biol 22:1961-1970

Lee WT, Yin HS, Shen YZ (2002) The mechanisms of neuronal death produced by mitochondrial toxin 3-nitropropionic acid: The roles of N-methyl-D-aspartate glutamate receptors and mitochondrial calcium overload. Neuroscience 112:707-716

Liu FC, Graybiel AM (1996) Spatiotemporal dynamics of CREB phosphorylation: transient versus sustained phosphorylation in the developing striatum. Neuron 17:1133-1144

Lu B, Pang PT, Woo NH (2005) The yin and yang of neurotrophin action. Nat Rev Neurosci 6:603-614
Matthews RP, Guthrie CR, Wailes LM, Zhao X, Means AR, McKnight GS (1994) Calcium/calmodulin-dependent protein kinase types II and IV differentially regulate CREB-dependent gene expression. Mol Cell Biol 14:6107-6116

Mayr B, Montminy M (2001) Transcriptional regulation by the phosphorylation-dependent factor CREB. Nat Rev Mol Cell Biol 2:599-609

Mimnaugh EG, Kayastha G, McGovern NB, Hwang SG, Marcu MG, Trepel J, Cai SY, Marchesi VT, Neckers L (2001) Caspasedependent deubiquitination of monoubiquitinated nucleosomal histone H2A induced by diverse apoptogenic stimuli. Cell Death Differ 8:1182-1196

Napolitano M, Centonze D, Gubellini P, Rossi S, Spiezia S, Bernardi G, Gulino A, Calabresi P (2004) Inhibition of mitochondrial complex II alters striatal expression of genes involved in glutamatergic and dopaminergic signaling: possible implications for Huntington's disease. Neurobiol Dis 15:407-414

Panteleeva I, Rouaux C, Larmet Y, Boutillier S, Loeffler JP, Boutillier AL (2004) HDAC-3 participates in the repression of e2fdependent gene transcription in primary differentiated neurons. Ann N Y Acad Sci 1030:656-660

Paroni G, Mizzau M, Henderson C, Del Sal G, Schneider C, Brancolini C (2004) Caspase-dependent regulation of histone deacetylase 4 nuclear-cytoplasmic shuttling promotes apoptosis. Mol Biol Cell 15:2804-2818

Perkinton MS, Ip JK, Wood GL, Crossthwaite AJ, Wiltion RJ (2002) Phosphatidylinositol 3-kinase is a central mediator of NMDA receptor signalling to MAP kinase (Erk1/2), Akt/PKB and CREB in striatal neurones. J Neurochem 80:239-254

Rouaux C, Jokic N, Mbebi C, Boutillier S, Loeffler JP, Boutillier AL (2003) Critical loss of $\mathrm{CBP} / \mathrm{p} 300$ histone acetylase activity by caspase-6 during neurodegeneration. EMBO J 22:6537-6549

Saha RN, Pahan K (2006) HATs and HDACs in neurodegeneration: a tale of disconcerted acetylation homeostasis. Cell Death Differ 13:539-550

Santos AE, Carvalho AL, Lopes MC, Carvalho AP (2001) Differential postreceptor signaling events triggered by excitotoxic stimulation of different ionotropic glutamate receptors in retinal neurons. J Neurosci Res 66:643-655

Smith GC, d'Adda di Fagagna F, Lakin ND, Jackson SP (1999) Cleavage and inactivation of ATM during apoptosis. Mol Cell Biol 19:6076-6084

Talasz H, Helliger W, Sarg B, Debbage PL, Puschendorf B, Lindner H (2002) Hyperphosphorylation of histone H2A.X and dephosphorylation of histone $\mathrm{H} 1$ subtypes in the course of apoptosis. Cell Death Differ 9:27-39

Wu GY, Deisseroth K, Tsien RW (2001) Activity-dependent CREB phosphorylation: convergence of a fast, sensitive calmodulin kinase pathway and a slow, less sensitive mitogen-activated protein kinase pathway. Proc Natl Acad Sci USA 98:2808-2813

Yamamoto KK, Gonzalez GA, Biggs WH, Montminy MR (1988) Phosphorylation-induced binding and transcriptional efficacy of nuclear factor CREB. Nature 334:494-498 